\title{
Solid-Liquid-Vapor Equilibrium Prediction for Typical Helium- Bearing Natural Gas Mixtures
}

\author{
Elvira Spatolisano and Laura A. Pellegrini*
}

Cite This: J. Chem. Eng. Data 2021, 66, 4122-4131

Read Online

ABSTRACT: Industrial, large-scale helium recovery from natural gas is typically performed though cryogenic distillation. These technologies need a deep knowledge of the thermodynamics of the treated mixture: in the case of natural gas to a pipeline, $\mathrm{CO}_{2}$ present in the feed stream might freeze at the process operating temperatures. The aim of this work is to analyze the thermodynamic behavior of the four-component mixture $\mathrm{CH}_{4}-\mathrm{N}_{2}-\mathrm{He}-$ $\mathrm{CO}_{2}$ to predict its triphasic solid-liquid-vapor equilibrium (SLVE). Through a developed computational method based on the classical approach, the nitrogen and helium effect on $\mathrm{CO}_{2}$ solidification has been assessed. The investigated conditions are consistent with typical cryogenic procesthesing temperatures (i.e., 100-200 K) and natural gas compositions.

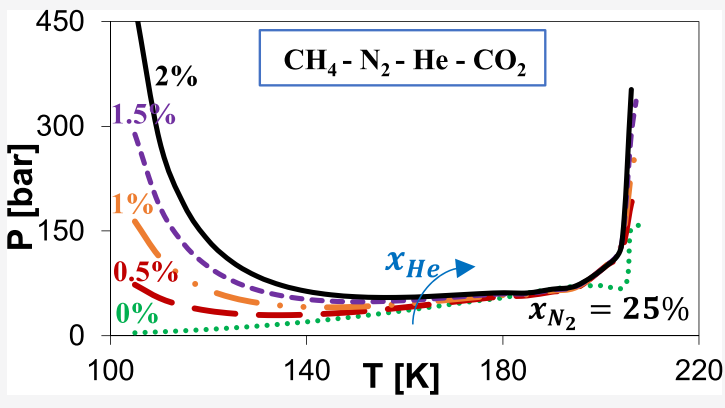
Pressure-temperature and temperature-composition equilibrium loci are provided for each analyzed case, varying the $\mathrm{N}_{2}$ and $\mathrm{He}$ content in mixture. Helium behavior as a quantum gas has been considered by introducing temperature-dependent critical parameters, as suggested by Prausnitz and co-workers, valid for an acentric factor equal to zero. Referring to the proposed thermodynamic modeling, the risk of $\mathrm{CO}_{2}$ freezing within a cryogenic helium recovery plant can be avoided by carefully managing the process operating conditions.

\section{INTRODUCTION}

Helium is an extraordinary commodity. Its atomic configuration is responsible for a number of extreme physical and chemical properties, which allow this element to play a crucial role in many of the most advanced technological sectors. ${ }^{1}$

Cryogenic applications exploit a massive portion of the total helium production (about 30\% of the U.S. helium consumption in $2019^{2}$ ). Specifically, the magnetic resonance imaging (MRI) equipment requires, for superconductive magnet cooling, nearly $1700 \mathrm{~L}$ of liquid helium for operation and around $30 \mathrm{~L}$ of liquid helium to be added every 2 months.

Other medical applications are related to magnetoencephalography (MEG), helium-neon lasers for eye surgery, and cooling thermographic cameras used to monitor certain physiological processes. Helium is also of extreme importance in producing helium/oxygen breathing gas mixtures $\left(20 \% \mathrm{O}_{2}-\right.$ $80 \% \mathrm{He})$ to avoid nitrogen narcosis in deep-sea divers and operating-room patients.

Since its molecular size is the smallest of any element, helium passes easily through the narrowest gaps, proving to be a sensitive means of leak detection for pipelines, heat exchangers, and valves. ${ }^{3}$

Helium inertness is particularly appreciated in semiconductor manufacturing and in gas chromatography, whereas its lightness finds use in lifting airships and balloons for upper atmosphere and cosmic ray studies as well as weather forecasting and, of course, toy balloons.
Optical fiber production and metallurgic processes exploit helium superconductivity, as they require rapid cooling. For the same reason, helium is a cooling medium for hightemperature nuclear reactors: next-generation gas-cooled reactors prove to be more efficient and safer than traditional water-cooled ones. ${ }^{4}$

Although air contains a large volume of helium, its concentration of $5 \mathrm{ppm}^{5}$ is too low for viable gas extraction from the atmosphere. The only practical helium sources are certain natural gas (NG) fields. Typical helium concentrations in natural gas range between 0 and $2 \mathrm{~mol} \%$ for helium-rich gas fields, being the extraction process favored if the helium content greater than $0.3 \mathrm{~mol} \%{ }^{5}$

Typical helium-bearing natural gas compositions are listed in Table 1.

In all cases, helium requires a carrier gas (i.e., nitrogen) to be collected in a gas reservoir.

Special Issue: In Honor of A. E. Mather

Received: April 30, 2021

Accepted: July 14, 2021

Published: July 28, 2021

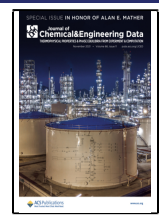


Table 1. Typical Helium-Bearing Natural Gas Compositions ${ }^{a}$

\begin{tabular}{|c|c|c|c|c|c|c|c|c|}
\hline & Keyes & San Juan & Young & Otis & Worsley & Ostrow & Hassi R'Mel & Northern Territory \\
\hline & (Oklahoma) & (New Mexico) & (Texas) & (USA) & (Canada) & (Poland) & (Algeria) & (Australia) \\
\hline $\mathrm{He}[\mathrm{mol} \%]$ & 2.1 & 4.05 & 1.17 & 1.4 & 0.53 & 0.4 & 0.19 & 0.21 \\
\hline $\mathrm{N}_{2}[\mathrm{~mol} \mathrm{\%}]$ & 26.3 & 45 & 31.1 & 12.7 & 6 & 43 & 5.8 & 2.3 \\
\hline $\mathrm{C}_{m} \mathrm{H}_{n}[\mathrm{~mol} \%]$ & 71.6 & 50.05 & 67.63 & 85.9 & 93 & 56.3 & 93.81 & 97.39 \\
\hline $\mathrm{CO}_{2}[\mathrm{~mol} \mathrm{\%}]$ & & 0.9 & 0.1 & & 0.47 & 0.3 & 0.2 & 0.1 \\
\hline
\end{tabular}

${ }^{a}$ The hydrocarbon content is grouped in the $\mathrm{C}_{m} \mathrm{H}_{n}$ contribution. ${ }^{6-9}$

Carbon dioxide is also usually found in some helium-bearing formations, but the presence of this gas is primarily due to its proximity to ancient volcanic activity.

The total helium reserves and resources, according to the last updated Mineral Commodity Summaries, were estimated to be 51.9 billion cubic meters. Measured U.S. reserves include 670 million cubic meters of helium stored in the Cliffside Field Government Reserve and 65 million cubic meters of helium contained in the Cliffside Field native gas. The Cliffside (Texas), Hugoton (Kansas, Oklahoma, and Texas), Panhandle West (Texas), Panoma (Kansas), and Riley Ridge (Wyoming) fields are depleted fields from which most U.S.-produced helium is extracted. These fields contain an estimated 3.9 billion cubic meters of helium.

The locations and volumes of other major deposits outside the United States are, in billion cubic meters, Qatar, 10.1; Algeria, 8.2; Russia, 6.8; Canada, 2.0; and China, 1.1.

Because helium demand is expected to increase in the near future, the value of these helium-bearing NG fields is likely to rise significantly.

Almost the entire existing helium extraction facilities use cryogenic separation technology. ${ }^{10,11}$

For the development of highly efficient cryogenic removal processes, a deep knowledge of the thermodynamics of the treated mixture is needed. Being that helium recovery is the last step in the natural gas purification chain, the feed mixture to the helium recovery section is the quaternary mixture $\mathrm{CH}_{4}-$ $\mathrm{N}_{2}-\mathrm{He}-\mathrm{CO}_{2}$.

Cryogenic distillation processes integrating helium recovery from natural gas involve very low temperatures, suggesting the possibility of $\mathrm{CO}_{2}$ solid deposit formation, eventually responsible for equipment blockage and damage, in the case of pipeline-quality natural gas production. ${ }^{12,13}$

In this work, a thermodynamic method based on the cubic equations of state $(\mathrm{CEoS})$ is used to investigate the behavior of the $\mathrm{CH}_{4}-\mathrm{N}_{2}-\mathrm{He}-\mathrm{CO}_{2}$ mixture.

The Peng-Robinson ${ }^{14}$ (PR) equation of state has been selected for this purpose and is regarded as particularly suitable for the system under investigation. ${ }^{15}$

In the application of the fugacity equations for liquid and vapor phases, specific attention is required in the definition of helium critical parameters: as a quantum gas, the corresponding state approach is not adequate to describe its properties, which are determined on the basis of modified temperaturedependent effective critical constants. ${ }^{16,17}$

The study of the solid-liquid-vapor equilibrium (SLVE) for $\mathrm{CH}_{4}-\mathrm{N}_{2}-\mathrm{He}-\mathrm{CO}_{2}$ mixtures enables the detection of the possible coexistence of solid $\mathrm{CO}_{2}$ with the liquid and vapor phases naturally involved in the distillation process.

Variable $\mathrm{N}_{2}$ and $\mathrm{He}$ contents are considered in the present analysis, consistently with typical natural gas compositions. In this way, the effect of nitrogen, helium, and their combination on $\mathrm{CO}_{2}$ freezing can be assessed, allowing the identification of suitable cryogenic processes and operating conditions.

\section{THERMODYNAMICS}

When dealing with a phase equilibrium problem, eq 1 resumes the necessary conditions for a heterogeneous closed system consisting of $N$ components arranged in $\pi$ phases. As stated by eq 1 , temperature $T$, pressure $P$, and chemical potential $\mu$, which govern the repartition of the molecules in different phases, must be equal for each component in each phase. ${ }^{18}$

$$
\left\{\begin{array}{l}
T^{1}=T^{2}=\ldots=T^{\pi} \\
P^{1}=P^{2}=\ldots=P^{\pi} \\
\mu_{1}^{1}=\mu_{1}^{2}=\ldots=\mu_{1}^{\pi} \\
\cdots \\
\mu_{N}^{1}=\mu_{N}^{2}=\ldots=\mu_{N}^{\pi}
\end{array}\right.
$$

Considering the relationship between the chemical potential and the fugacity $f$ for a generic $i$ component in a mixture, the chemical potential equalities result in the well-known isofugacity conditions.

Regarding vapor-liquid equilibrium conditions, two approaches are commonly used for describing the isofugacity condition: the symmetric and the asymmetric ones, also known as, respectively, $\varphi-\varphi$ and $\gamma-\varphi$ approaches.

When equilibria calculations also involve the solid phase, two alternative methods can be used to model solid-fluid equilibrium: the classical approach (CA), based on classical thermodynamic relations, and the nonclassical approach (NCA), in which the solid phase is modeled through an ad hoc modification of traditional EoSs. ${ }^{19}$ Several studies are available in the literature for this purpose. ${ }^{20-22}$

The first attempt of describing SLVE through a suitable modification of a traditional equation of state is dated back to $1979 .^{20}$ Kan developed a pressure-explicit equation, namely, the modified cubic EoS (MCEoS), where the last term takes into account the attractive contribution of the solid phase.

Salim and Trebble ${ }^{21}$ then proposed a system of two cubic EoSs (SCEoSs) to allow the calculation of thermodynamic properties of the three main states of matter as well as the corresponding equilibria.

In 2003, Yokozeki modified the repulsive term of a CEoS for representing the phase behavior of solid, liquid, and vapor phases with a single analytical equation. ${ }^{22}$ The result was a quartic equation of state (QEoS) that allows the prediction of equilibria adopting a unified approach for all of the phases.

On the other hand, in the classical method the solid state is usually treated as a separate and different thermodynamic equation at the phase transition, and then the phase equilibrium is solved by combining the fluid-phase EOS. ${ }^{23}$ 
According to the classical approach followed in this article, the pure-component solid phase fugacity can be determined by imposing, for instance, solid-liquid equilibrium conditions.

Under the assumption of constant liquid and solid heat capacities and being enthalpy and entropy state functions (Figure 1), the Gibbs free energy variation can be evaluated

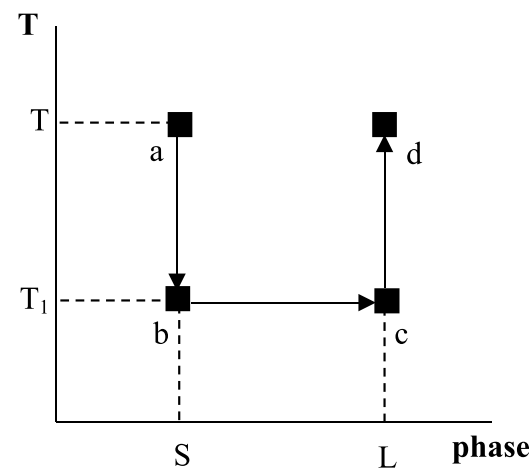

Figure 1. Thermodynamic path for SLE from enthalpy and entropy variations.

according to eq 2, while eq 3 allows the determination of the solid-phase fugacity $\phi^{\text {s. }}$.

$$
\begin{aligned}
& \Delta G_{\text {melt }}(T, P)=\left(c p^{\mathrm{S}}-c p^{\mathrm{L}}\right)\left(T_{1}-T-T \ln \left(\frac{T_{1}}{T}\right)\right) \\
& +\Delta H_{\text {melt }}\left(T_{1}, P_{1}\right)\left(1-\frac{T}{T_{1}}\right) \\
& \phi^{\mathrm{S}}(T, P)=\phi^{\mathrm{L}}(T, P) \exp \left(\frac{c p^{\mathrm{S}}-c p^{\mathrm{L}}}{R}\left(\frac{T_{1}}{T}-1-\ln \left(\frac{T_{1}}{T}\right)\right)\right. \\
& \left.+\frac{\Delta H_{\text {melt }}\left(T_{1}, P_{1}\right)}{R}\left(\frac{1}{T}-\frac{1}{T_{1}}\right)\right)
\end{aligned}
$$

An ad hoc Fortran routine has been developed for the analysis of the triphasic SLVE problem, whose details are provided in section 3 . $^{24}$

\section{COMPUTATIONAL METHOD}

A Fortran routine has been developed to solve SLVE problem typical of cryogenic separations involved in the natural gas purification chain.

In the analyzed systems, each component is distributed in the liquid and vapor phase, depending on the operating conditions selected, while in the solid phase only $\mathrm{CO}_{2}$ is present. For this reason, the physical equilibrium of the considered mixtures can be described according to the following equations:

$$
\begin{aligned}
& f_{\mathrm{CO}_{2}}^{\mathrm{S}}(T, P)=\hat{f}_{\mathrm{CO}_{2}}^{\mathrm{L}}(T, P, \tilde{x})=\hat{f}_{\mathrm{CO}_{2}}^{\mathrm{V}}(T, P, \tilde{y}) \\
& \hat{f}_{i}^{\mathrm{L}}(T, P, \tilde{x})=\hat{f}_{i}^{\mathrm{V}}(T, P, \tilde{y}), i \neq \mathrm{CO}_{2}
\end{aligned}
$$

The component fugacity is determined through a direct approach $(\phi-\phi$, eqs 6 and 7$)$, where the Peng-Robinson equation of state (PREoS) has been selected for the evaluation of fugacity coefficients (eq 8 ) in liquid and vapor phases. In eq $8, Z$ is the compressibility factor, evaluated by solving the
PREoS; $a, b, A$, and $B$ are mixture parameters, to be calculated with the appropriate combination and mixing rules, while $b_{i}$ is associated with pure component $i$.

On the other hand, the $\mathrm{CO}_{2}$ solid-phase fugacity is expressed as a function of the fugacity in the liquid phase at the same temperature and pressure, exploiting the solid-liquid equilibrium for pure $\mathrm{CO}_{2}$ (eq 3 ).

$\mathrm{CO}_{2}$ solubility $\left(x_{\mathrm{CO}_{2}}^{\text {sat }}\right)$ can be evaluated starting from liquidsolid equilibrium conditions, through eq 9.

$$
\begin{aligned}
& \phi_{\mathrm{CO}_{2}}^{\mathrm{S}}(T, P)=\hat{\phi}_{\mathrm{CO}_{2}}^{\mathrm{L}}(T, P, \tilde{x}) x_{\mathrm{CO}_{2}}=\hat{\phi}_{\mathrm{CO}_{2}}^{\mathrm{V}}(T, P, \tilde{y}) y_{\mathrm{CO}_{2}} \\
& \hat{\phi}_{i}^{\mathrm{L}}(T, P, \tilde{x}) x_{i}=\hat{\phi}_{i}^{\mathrm{V}}(T, P, \tilde{y}) y_{i}, \quad i \neq \mathrm{CO}_{2} \\
& \ln \hat{\phi}_{i}=\frac{b_{i}}{b}(Z-1)-\ln (Z-B)+\frac{A}{2 \sqrt{2} B} \\
& \left(\frac{b_{i}}{b}-2 \frac{\sum_{j=1}^{N} x_{j} a_{i j}}{a}\right) \ln \left(\frac{Z+B(1+\sqrt{2})}{Z+B(1-\sqrt{2})}\right) \\
& x_{\mathrm{CO}_{2}}^{\text {sat }}=\frac{\phi_{\mathrm{CO}_{2}}^{\mathrm{L}}(T, P) \exp \left(\frac{c p^{\mathrm{S}}-c p^{\mathrm{L}}}{R}\left(\frac{T_{1}}{T}-1-\ln \left(\frac{T_{1}}{T}\right)\right)+\frac{\Delta H_{\mathrm{melt}}\left(T_{1}, P_{1}\right)}{R}\left(\frac{1}{T}-\frac{1}{T_{1}}\right)\right)}{\hat{\phi}_{\mathrm{CO}_{2}}^{\mathrm{L}}(T, P, \tilde{x})}
\end{aligned}
$$

To begin calculations, the degrees of freedom (DOF) of the analyzed system, evaluated through the Gibbs phase rule (eq 10), have to be fixed, with $C$ being the number of components and $P$ being the number of phases involved in equilibrium calculations.

$$
\mathrm{DOF}=\mathrm{C}-\mathrm{P}+2
$$

To specify the system, temperature has always been assigned, as well as one or more component liquid-phase compositions $\left(x_{\mathrm{NC}-1}^{0}\right)$, according to the analyzed case.

At each iteration cycle, the program performs calculations according to Figure 2.

First, the $\mathrm{CO}_{2}$ liquid- and solid-phase fugacity coefficients are evaluated, according to the PREoS, considering the fixed temperature $T$ and the first attempt pressure $P^{0}$. Thanks to the liquid-phase fugacity coefficient, $\mathrm{CO}_{2}$ solubility can be determined according to eq 9. This calculated value is then compared with the resulting $n$th liquid-phase $\mathrm{CO}_{2}$ composi-

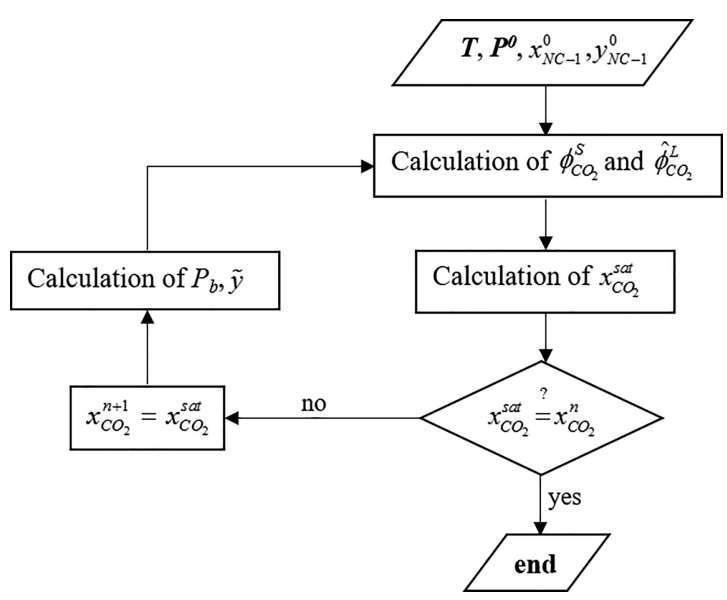

Figure 2. Fortran routine iteration loop structure. 
tion: if the equality between these two values is satisfied, then the program exits the iteration loop and the calculation is concluded. The calculated $\mathrm{CO}_{2}$ solubility has to be interpreted as the limiting $\mathrm{CO}_{2}$ liquid concentration just before solid deposition.

If this is not the case, the calculated $\mathrm{CO}_{2}$ solubility becomes the new liquid-phase $\mathrm{CO}_{2}$ composition.

Considering this new liquid-phase composition, a bubble pressure $\left(P_{\mathrm{b}}\right)$ problem has to be solved in order to update pressure and vapor-phase composition $(\tilde{y})$ values. The evaluated bubble pressure value is to be used for fugacity coefficient evaluation, and calculation proceeds until convergence.

A relative error of $10^{-6}$ between the $n$ and $n+1$ iteration is set as a limiting value to check the system convergence.

To perform the iterations, $\mathrm{CO}_{2}$ solid-phase properties and binary interaction parameters $k_{i j}$ for PREoS have been specified, as reported in Tables 2 and 3, respectively. ${ }^{24-26}$

Table 2. Solid-Phase $\mathrm{CO}_{2}$ Properties

$\begin{array}{lc}\quad \text { parameter } & \text { value } \\ \Delta H_{\text {melt }}{ }^{a} / R T & 4.6774 \\ -\left[\left(c p^{S}-c p^{\mathrm{L} b}\right) / R^{c}\right] & 0.9179 \\ T^{d}[\mathrm{~K}] & 216.39\end{array}$

${ }^{a} \Delta H_{\text {melt }}$ is the melting enthalpy variation. ${ }^{b} c p^{S}$ and $c p^{\mathrm{L}}$ are the constant pressure solid and liquid heat capacities, respectively. ${ }^{c} R$ is the universal gas constant. ${ }^{d} T$ is the melting temperature.

Table 3. Values of Binary Interaction Parameters $\left(k_{i j}\right)$ for PREoS

$\begin{array}{cc}i-j & k_{i j} \\ \mathrm{CH}_{4}-\mathrm{CO}_{2} & 0.1000 \\ \mathrm{~N}_{2}-\mathrm{CO}_{2} & -0.02 \\ \mathrm{He}-\mathrm{CO}_{2} & 0.7967 \\ \mathrm{CH}_{4}-\mathrm{N}_{2} & 0.0312\end{array}$

Binary interaction parameters are from Aspen HYSYS V9.0 27 simulation software databank.

For couples for which experimental data are available, the reliability of the developed routine for binary mixtures equilibrium predictions involving the solid phase has been extensively demonstrated. ${ }^{24,25}$

Once the method accuracy is proved for binary mixtures, the illustrated procedure has been applied to the three-component $\mathrm{CH}_{4}-\mathrm{N}_{2}-\mathrm{CO}_{2}$ and four-component $\mathrm{CH}_{4}-\mathrm{N}_{2}-\mathrm{He}-\mathrm{CO}_{2}$ mixtures to assess the effect of these light gases on $\mathrm{CO}_{2}$ solidification.

\section{APPLICATION TO $\mathrm{CH}_{4}-\mathrm{CO}_{2}-\mathrm{N}_{2}$ MIXTURES}

The $\mathrm{CH}_{4}-\mathrm{N}_{2}-\mathrm{CO}_{2}$ SLVE, being a three-component and three-phase equilibrium problem, presents two DOFs, evaluated through eq 10. For this reason, it requires the assignment of two intensive variables to be completely defined. The DOF has been saturated by specifying the temperature in the range of interest for the cryogenic distillation process, that is, $120-220 \mathrm{~K}$, and the nitrogen liquid-phase molar fraction, from 0 to $20 \%$, according to typical nitrogen-rich natural gas compositions.

In this way, 3D (Figures 3 and 4) and 2D (Figures 5 and 6) equilibrium curves have been obtained.

Figures 3 and 5 show that the $\mathrm{CO}_{2}$ solubility increases at increasing temperature and decreases at higher nitrogen contents. At temperatures of as low as $140 \mathrm{~K}$ and above 210 $\mathrm{K}$, the solubility curves tend to coincide, whereas the influence of different nitrogen content can be appreciated in the middle region, between 180 and $210 \mathrm{~K}$. The solubility increases steeply at around $210 \mathrm{~K}$, surging abruptly with the highest nitrogen contents while rising more gently at lower nitrogen molar fractions.

From this evidence, focusing on the middle temperature range in particular, it seems that the presence of nitrogen in the $\mathrm{CH}_{4}-\mathrm{CO}_{2}-\mathrm{N}_{2}$ mixture has a negative influence on the system, facilitating the carbon dioxide solidification.

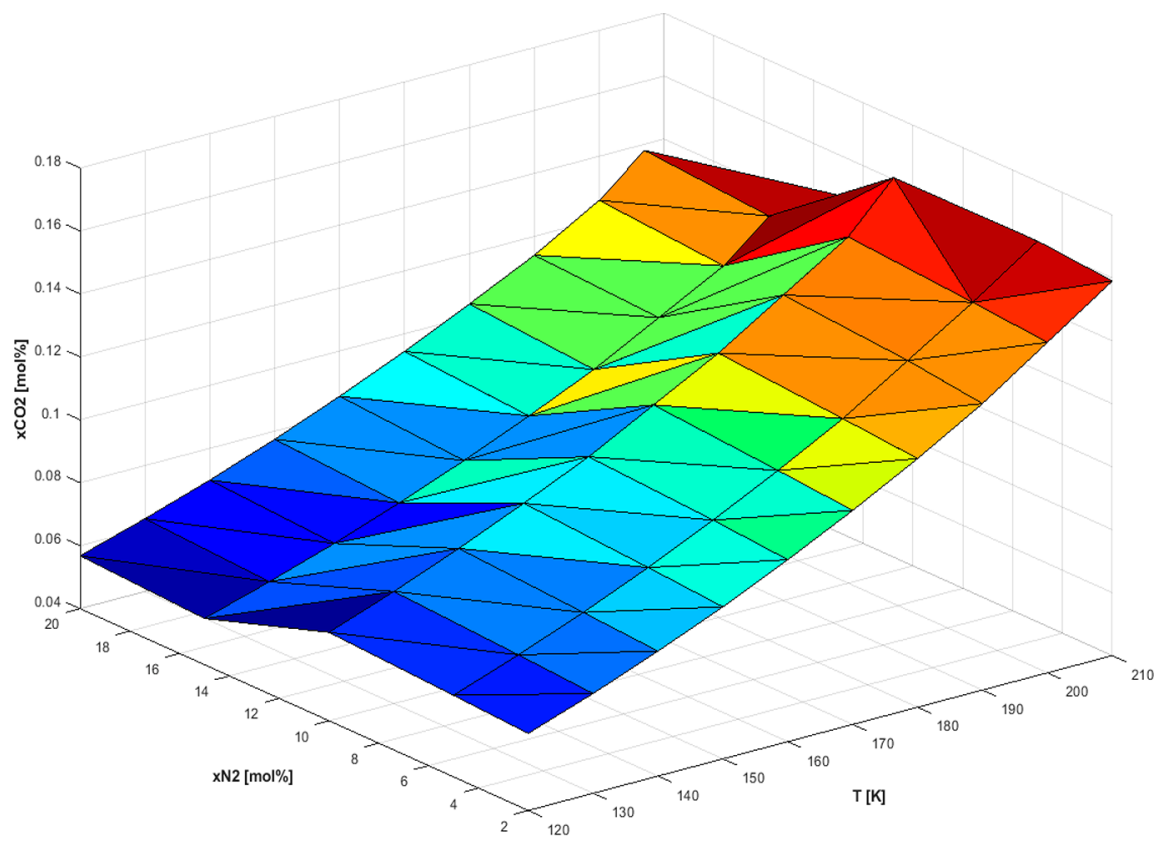

Figure 3. $\mathrm{CO}_{2}$ solubility representation for the $\mathrm{CH}_{4}-\mathrm{N}_{2}-\mathrm{CO}_{2}$ mixture in the $3 \mathrm{D}$ plane: $T, x_{\mathrm{N}_{2}}$, and $x_{\mathrm{CO}_{2}}$. 


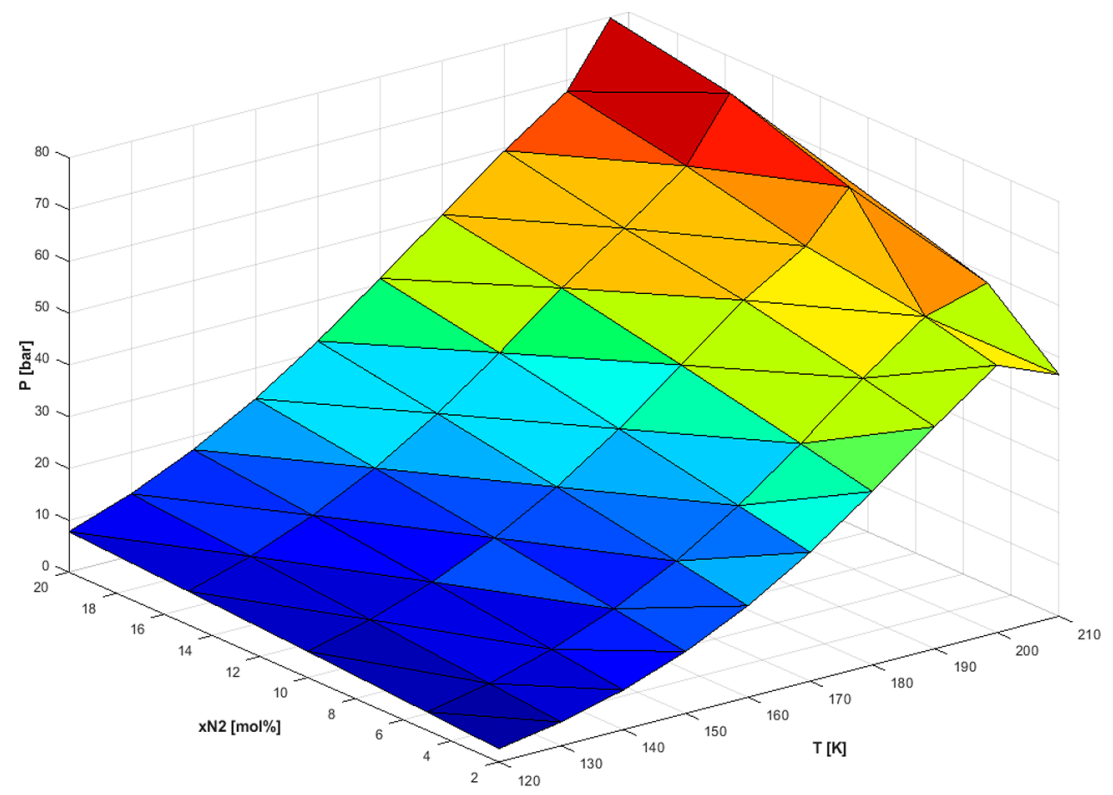

Figure 4. SLVE pressure representation for the $\mathrm{CH}_{4}-\mathrm{N}_{2}-\mathrm{CO}_{2}$ mixture in the $3 \mathrm{D}$ plane: $T, x_{\mathrm{N}_{2}}$, and $P$.

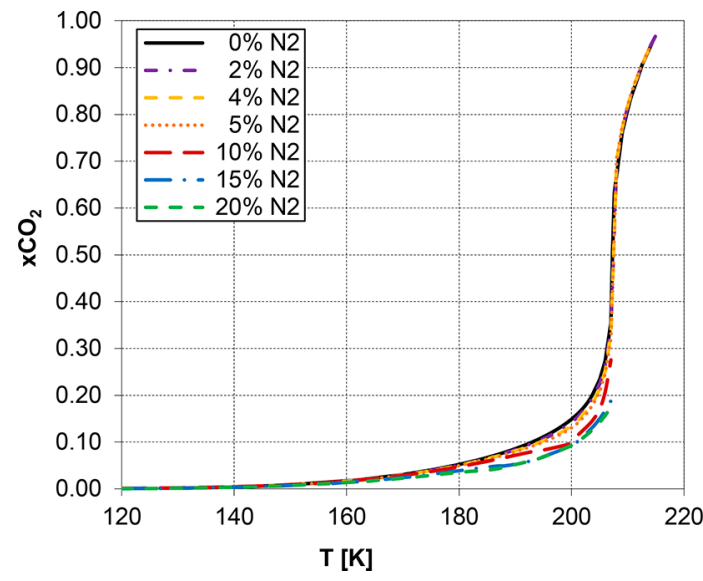

Figure 5. $\mathrm{CO}_{2}$ solubility $\left(x_{\mathrm{CO}_{2}}\right)$ vs temperature $T$ for the $\mathrm{CH}_{4}-\mathrm{N}_{2}-$ $\mathrm{CO}_{2}$ mixture at variable $\mathrm{N}_{2}$ liquid content.

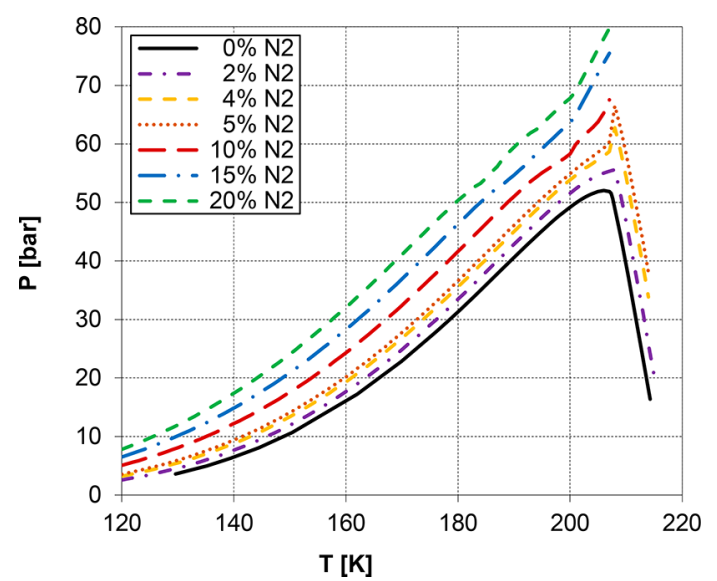

Figure 6. SLVE pressure $P$ vs temperature $T$ curves for the $\mathrm{CH}_{4}-\mathrm{N}_{2}-$ $\mathrm{CO}_{2}$ mixture at variable $\mathrm{N}_{2}$ liquid content.

Similar observations can be carried out by looking at the pressure-temperature curves, as reported in Figures 4 and 6.
At fixed temperature, the pressure increases with the nitrogen content, meaning that the SLVE locus shifts progressively toward higher pressures the greater the nitrogen molar fraction. Two different shapes of these curves can be observed: if for a $\mathrm{N}_{2}$ composition of up to $5 \mathrm{~mol} \%$ all of the curves show a clear maximum trend, at higher nitrogen percentages monotonic increasing behavior can be appreciated, with the curve reaching very high pressure values.

To assess the reliability of the developed method, model predictions have been compared with the available experimental data.

A large number of experimental studies provide $\mathrm{CO}_{2}$ solubility in liquid and vapor methane in the range of interest, going from the boiling temperature of liquefied natural gas (LNG) at atmospheric pressure (around $110 \mathrm{~K}$ ) to the boiling temperature at liquefaction pressure (around $180 \mathrm{~K}$ ), and some studies also provide the solubility of carbon dioxide in nitrogen. ${ }^{28}$ Unfortunately, there is a lack of experimental data regarding the three-component, three-phase mixture.

After a massive literature search, only a few experimental points by Riva and co-workers ${ }^{28}$ have been identified as suitable for the comparison.

In their work, two different mixtures are considered, whose global composition is reported in Table 4. These mixtures have

Table 4. Global Composition of the Loaded Mixture for Each Series of Measurements ${ }^{28}$

\begin{tabular}{|c|c|c|c|}
\hline & $\mathrm{N}_{2}$ & $\mathrm{CH}_{4}$ & $\mathrm{CO}_{2}$ \\
\hline$N$ & {$[\mathrm{~mol} / \mathrm{mol}]$} & {$[\mathrm{mol} / \mathrm{mol}]$} & {$[\mathrm{mol} / \mathrm{mol}]$} \\
\hline 1 & 0.4 & 0.58 & 0.02 \\
\hline 2 & 0.19 & 0.79 & 0.02 \\
\hline
\end{tabular}

been used to charge a refrigerated equilibrium cell whose temperature is fixed while both liquid- and vapor-phase compositions are measured, as well as pressure. Table 5 shows the experimental results, together with their uncertainties, provided by Riva and co-workers. 
Table 5. SLVE Experimental Liquid $(x)$ and Vapor $(y)$ Composition Measured for the Mixture of $\mathrm{N}_{2}(1)-\mathrm{CH}_{4}(3)-\mathrm{CO}_{2}(4)$ and the Corresponding Uncertainties $U^{a}$

$\left.\begin{array}{ccccccccc} & T & P & x_{3} & x_{4} & U\left(x_{4}\right) & y_{3} & \begin{array}{c}y_{4} \\ {[\mathrm{ppm}]}\end{array} \\ N & {[\mathrm{~K}]} & {[\mathrm{MPa}]} & {[-]} & {[\mathrm{ppm}]} & {[\mathrm{ppm}]} & 900 & 0.387 & 470 \\ {[\mathrm{ppm}]}\end{array}\right)$

${ }^{a} \mathrm{~N}$ is the series of measurements corresponding to the global composition reported in Table $4 .{ }^{28}$

For the same mixtures in Table 4, the equilibrium pressure and liquid- and vapor-phase compositions have been calculated with the developed Fortran routine, as outlined in Figure 2.

The obtained results are reported in Table 6.

Table 6. Fortran Routine: SLVE Liquid $(x)$ and Vapor $(y)$ Composition for the Mixture of $\mathrm{N}_{2}(1)-\mathrm{CH}_{4}(3)-\mathrm{CO}_{2}(4)$

\begin{tabular}{|c|c|c|c|c|c|c|}
\hline & $T$ & $P$ & $x_{1}$ & $x_{4}$ & $y_{1}$ & $y_{4}$ \\
\hline$N$ & {$[\mathrm{~K}]$} & {$[\mathrm{MPa}]$} & {$[-]$} & {$[-]$} & {$[-]$} & {$[-]$} \\
\hline 1.1 & 145.9 & 2.29 & 0.23 & $7.77 \times 10^{-3}$ & 0.60 & $4.69 \times 10^{-4}$ \\
\hline 1.2 & 132.1 & 1.55 & 0.26 & $2.82 \times 10^{-3}$ & 0.73 & $5.8 \times 10^{-5}$ \\
\hline 1.3 & 124.9 & 1.25 & 0.29 & $1.52 \times 10^{-3}$ & 0.79 & $1.6 \times 10^{-5}$ \\
\hline 2.1 & 145.8 & 1.57 & 0.11 & $8.45 \times 10^{-3}$ & 0.43 & $5.02 \times 10^{-4}$ \\
\hline 2.2 & 132.1 & 0.87 & 0.10 & $3.05 \times 10^{-3}$ & 0.52 & $7.5 \times 10^{-5}$ \\
\hline 2.3 & 124.5 & 0.56 & 0.08 & $1.58 \times 10^{-3}$ & 0.54 & $2.3 \times 10^{-5}$ \\
\hline
\end{tabular}

For further comparison, the same experimental points in Table 5 have also been evaluated using the Aspen HYSYS V9.0 $\mathrm{CO}_{2}$ freeze-out tool. ${ }^{29}$

This utility aids in the evaluation of potential $\mathrm{CO}_{2}$ freezing point for natural gas streams. The tool can be used to predict the initial solid formation point (temperature) in equilibrium with either a vapor, liquid, or (in a rare situation) an aqueous phase that exists under the stream conditions.

Depending on the equilibrium in which the user is interested, either solid-liquid (SL) or solid-vapor (SV), a phase has to be selected, and the tool gives a proper freezing temperature.

The limit of this tool is that it is capable of considering biphasic equilibrium only, without investigating the possible presence of triphasic equilibrium, which is the object of the present study.

To overcome this limit, a specific nonautomatic iterative methodology has been implemented to estimate the SLVE conditions for different mixtures through the process simulator.

Nevertheless, this method is time-consuming, and numerical problems hinder the system convergence in most cases.

Results from Aspen HYSYS V9.0 simulation software are provided in Table 7.

This comparison points out that the available experimental data are not in good agreement with the model predictions. Nevertheless, the Fortran routine and Aspen HYSYS V9.0 model predictions seem to be in good agreement. In this comparison, the fitting model proposed by Riva and coworkers, based on the Groupe Européen de Recherches Gazières (GERG) EoS, ${ }^{30}$ has also been considered.

Its predictions appear to overlap with the model developed in the present work for both mixtures ( 1 and 2): no
Table 7. Aspen HYSYS V9.0 $\mathrm{CO}_{2}$ Freeze-Out: SLVE Liquid $(x)$ and Vapor $(y)$ Composition for the Mixture of $\mathrm{N}_{2}(1)-$ $\mathrm{CH}_{4}(3)-\mathrm{CO}_{2}(4)^{a}$

\begin{tabular}{|c|c|c|c|c|c|c|}
\hline & $T$ & $P$ & $x_{1}$ & $x_{4}$ & $y_{1}$ & $y_{4}$ \\
\hline$N$ & {$[\mathrm{~K}]$} & [MPa & {$[-]$} & {$[-]$} & {$[-]$} & {$[-]$} \\
\hline 1.1 & 145.4 & 1.55 & 0.11 & $5.72 \times 10^{-3}$ & 0.43 & $3.39 \times 10^{-4}$ \\
\hline 1.2 & 131.6 & 1.52 & 0.26 & 0.0016 & 0.73 & $3.29 \times 10^{-5}$ \\
\hline 1.3 & 123.8 & 1.19 & 0.29 & $7.49 \times 10^{-4}$ & 0.80 & $7.29 \times 10^{-6}$ \\
\hline 2.1 & 146 & 2.29 & 0.23 & $5.45 \times 10^{-3}$ & 0.59 & $3.37 \times 10^{-4}$ \\
\hline 2.2 & 132 & 1.55 & 0.26 & $1.85 \times 10^{-3}$ & 0.72 & $3.62 \times 10^{-5}$ \\
\hline 2.3 & 125 & 1.25 & 0.29 & $8.65 \times 10^{-4}$ & 0.79 & $9.14 \times 10^{-6}$ \\
\hline
\end{tabular}

${ }^{a}$ Considering the experimental points of Table 5 and the model results of Tables 6 and 7 , a comparison is performed on the solubility-temperature diagram, reported in Figure 7.

appreciable difference between these two can be observed in Figure 7.

This evidence suggests that the experimental points considered for the comparison are affected by errors due to the intrinsic difficulty of measurements caused by the very low concentrations (on the order of ppm), as also suggested by the authors.

\section{EXTENSION TO HE-CONTAINING MIXTURES}

The triphasic equilibrium of the $\mathrm{CH}_{4}-\mathrm{N}_{2}-\mathrm{He}-\mathrm{CO}_{2}$ system requires three DOFs to be fixed, according to eq 10 . These DOFs are saturated by assigning the equilibrium temperature and both $\mathrm{N}_{2}$ and $\mathrm{He}$ molar fractions in the liquid phase.

To segregate the single effects of $\mathrm{N}_{2}$ and $\mathrm{He}$ on $\mathrm{CO}_{2}$ solidification, two different simulation sets have been performed: the first one keeps the helium content fixed at 2 $\mathrm{mol} \%$ and varies the nitrogen content from 5 to $35 \mathrm{~mol} \%$, and the second one imposes a nitrogen fraction equal to $25 \mathrm{~mol} \%$ with helium content ranging from 0 to $2 \mathrm{~mol} \%$. The investigated helium composition range is severely narrower than the corresponding one for nitrogen and coincides with the common helium contents of helium-bearing natural gases.

The temperature range investigated is the same as that in section 4.

When applying the developed calculation method to helium mixtures, attention has to be paid to its configurational properties. Because helium is a quantum gas, the corresponding-states law applied to classical gases fails in predicting its behavior.

This problem is most severe for helium because it has one of the lowest critical temperatures of any gas $(5.1953 \mathrm{~K}) .^{31}$

Attempts to rectify the cubic equations of state to accommodate quantum gases can be classified into four categories: (1) those where the true critical temperature is 

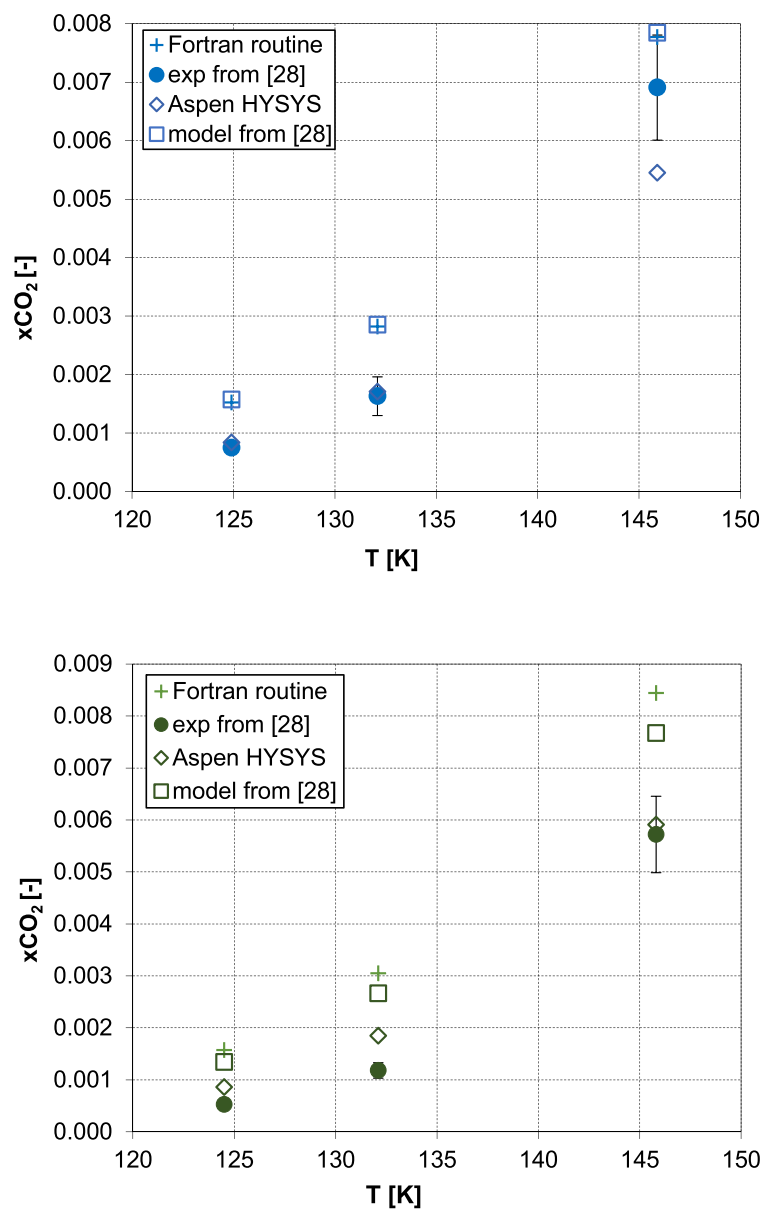

b)

Figure 7. $\mathrm{CO}_{2}$ solubility $\left(x_{\mathrm{CO}_{2}}\right)$ vs temperature $T$ for the $\mathrm{CH}_{4}-\mathrm{N}_{2}-$ $\mathrm{CO}_{2}$ mixture. Comparison between models and experimental data from ref 28 for (a) mixture 1 and (b) mixture 2 .

substituted with an "effective" critical temperature; ${ }^{16,17}$ those with novel temperature-dependent functions in the attractive term of the equation of state $;^{32-34}$ (3) those with novel mixing terms; ${ }^{35}$ and (4) those with temperaturedependent binary interaction parameters. ${ }^{15,36,37}$

In this work, category (1) has been considered: temperaturedependent, effective critical constants have been introduced, with which the properties of quantum gases can be made to coincide with those for classical gases.

These quantum corrections, valid for helium acentric factor $\omega=0$, are provided in eqs 11 and 12 , with $T_{\mathrm{c}}^{0}$ and $P_{\mathrm{c}}^{0}$ being the true helium critical temperature and pressure, respectively, and $m$ being its molecular weight.

$$
\begin{aligned}
& T_{\mathrm{c}}=\frac{T_{\mathrm{c}}^{0}}{1+\frac{c_{1}}{m T}} \text { with } c_{1}=21.8 \mathrm{~K} \\
& P_{\mathrm{c}}=\frac{P_{\mathrm{c}}^{0}}{1+\frac{c_{2}}{m T}} \text { with } c_{2}=44.2 \mathrm{~K}
\end{aligned}
$$

By introducing eqs 11 and 12 into the calculation method discussed in section 3, SLVE loci for the four-component mixture have been obtained.
Figure 8 shows the nitrogen effects on the $\mathrm{CO}_{2}$ solubility in the $\mathrm{CH}_{4}-\mathrm{N}_{2}-\mathrm{He}-\mathrm{CO}_{2}$ system. The helium molar fraction in the liquid phase is kept constant and equal to $2 \mathrm{~mol} \%$.

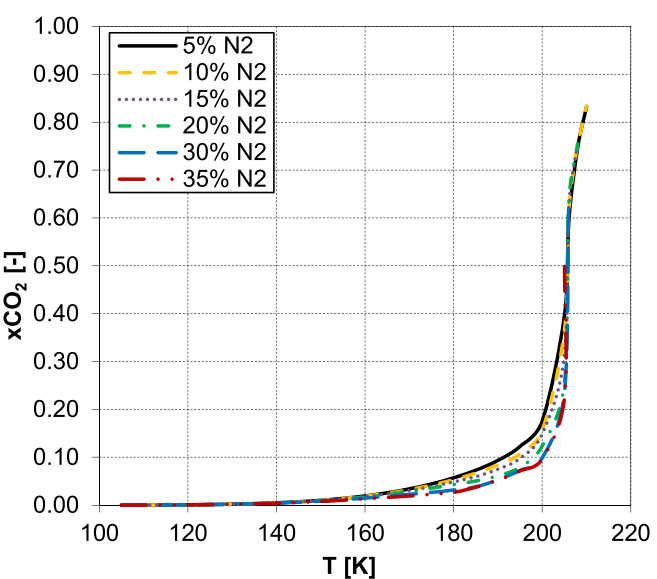

Figure 8. $\mathrm{CO}_{2}$ solubility $\left(x_{\mathrm{CO}_{2}}\right)$ vs temperature $T$ for the $\mathrm{CH}_{4}-\mathrm{N}_{2}-$ $\mathrm{He}-\mathrm{CO}_{2}$ mixture at variable $\mathrm{N}_{2}$ liquid content. The helium molar fraction in the liquid phase is equal to $2 \mathrm{~mol} \%$.

Similarly to the results in section $4, \mathrm{CO}_{2}$ solubility increases with temperature while decreasing at a higher nitrogen content. In Figure 8, it can be appreciated how the discrepancies between the different nitrogen content curves fade in the two extreme regions below $140 \mathrm{~K}$ and above $210 \mathrm{~K}$ but are distinctively evident in the intermediate range, between 160 and $200 \mathrm{~K}$.

Above $200 \mathrm{~K}$, the slope of the solubility curves increases steeply, much more for high nitrogen fraction and more gently for lower nitrogen contents.

The corresponding pressure-temperature equilibrium curves are provided in Figure 9.

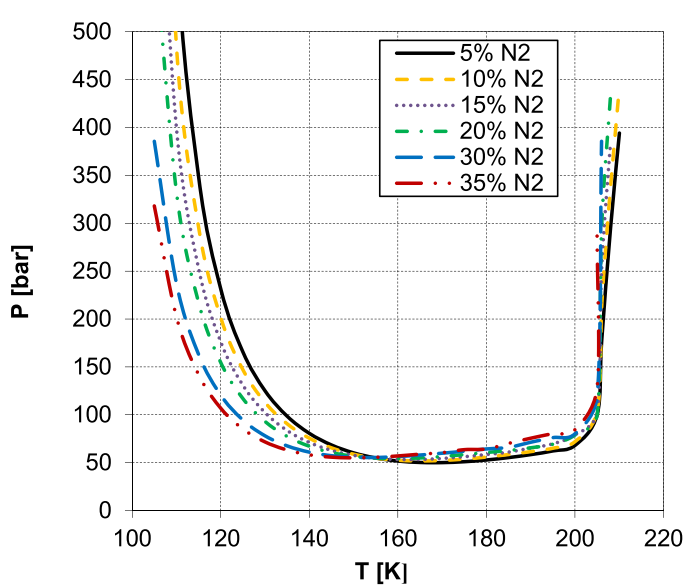

Figure 9. SLVE pressure $P$ vs temperature $T$ curves for $\mathrm{CH}_{4}-\mathrm{N}_{2}-$ $\mathrm{He}-\mathrm{CO}_{2}$ at variable $\mathrm{N}_{2}$ liquid content. The helium molar fraction in the liquid phase is equal to $2 \mathrm{~mol} \%$.

All of the equilibrium curves in Figure 9 show a minimum in the middle temperature range, which is shifted toward higher temperatures at decreasing nitrogen content. Pressure decreases more gently in the lower temperature region but rises abruptly above $200 \mathrm{~K}$. 
In Figure 9, two opposite trends can be recognized: one above $155 \mathrm{~K}$ and the other below $155 \mathrm{~K}$.

Above $155 \mathrm{~K}$, the SLVE locus exhibits higher pressure at increasing nitrogen content, in agreement with the outcomes of section 4 on the $\mathrm{CH}_{4}-\mathrm{N}_{2}-\mathrm{CO}_{2}$ mixture. However, below $155 \mathrm{~K}$ helium causes a trend inversion, which is not observed for the ternary mixture $\mathrm{CH}_{4}-\mathrm{N}_{2}-\mathrm{CO}_{2}$.

The assessment of helium's influence on $\mathrm{CO}_{2}$ solidification originates from the analysis of the SLVE curves obtained at a fixed nitrogen fraction in the liquid phase, kept constant at $25 \%$ mol.

Results from this analysis are represented in Figures 10 and 11.

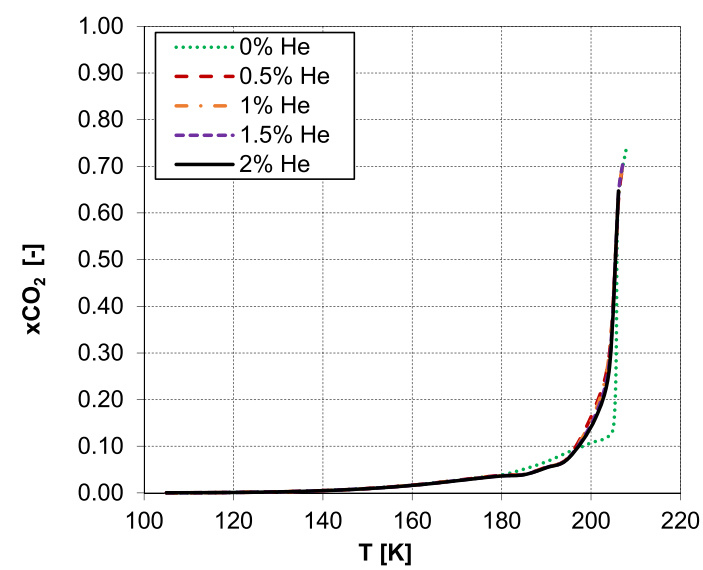

Figure 10. $\mathrm{CO}_{2}$ solubility $\left(x_{\mathrm{CO}_{2}}\right)$ vs temperature $T$ for the $\mathrm{CH}_{4}-\mathrm{N}_{2}-$ $\mathrm{He}-\mathrm{CO}_{2}$ mixture at variable $\mathrm{He}$ liquid content. The nitrogen molar fraction in the liquid phase is equal to $25 \mathrm{~mol} \%$.

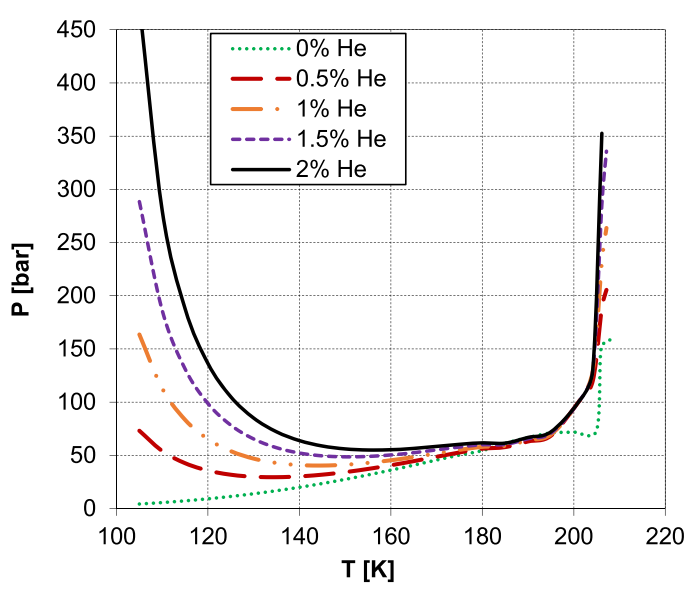

Figure 11. SLVE pressure $P$ vs temperature $T$ curves for the $\mathrm{CH}_{4}-$ $\mathrm{N}_{2}-\mathrm{He}-\mathrm{CO}_{2}$ mixture at variable $\mathrm{He}$ liquid content. The nitrogen molar fraction in the liquid phase is equal to $25 \mathrm{~mol} \%$.

Figure 10 shows the $\mathrm{CO}_{2}$ solubility plots at variable helium content in the liquid phase. The nitrogen molar fraction in the liquid phase is kept constant and equal to $25 \mathrm{~mol} \%$.

As pointed out in Figure 10, a nearly complete overlap of the curves can be noticed due to the low imposed variation in the liquid helium content. The only curve that differs from the general trend is associated with a null helium content, but it is in agreement with the outcome of section 4 for the $\mathrm{CH}_{4}-\mathrm{N}_{2}-$ $\mathrm{CO}_{2}$ mixture.
The corresponding pressure-temperature equilibrium curves are provided in Figure 11.

All of the equilibrium loci except the case at $0 \mathrm{~mol} \%$ helium exhibit a flattened minimum, progressively shifted rightward as the helium content increases. A clear distinction between the curves can be appreciated below $180 \mathrm{~K}$ and in correspondence with the highest temperatures investigated, while in the middle region the discrepancies are progressively reduced until the curves seem to be nearly overlapped. Throughout the whole range of temperatures investigated, the SLV equilibrium pressure increases with helium content. Thus, it can be deduced that helium behaves like nitrogen: it enhances $\mathrm{CO}_{2}$ solidification.

For the $\mathrm{CH}_{4}-\mathrm{N}_{2}-\mathrm{He}-\mathrm{CO}_{2}$ mixture, no experimental SLVE data are available in the literature to evaluate the reliability of the model predictions. The severe equilibrium temperature and pressure probably make experimental point collection difficult.

For this reason, a comparison with Aspen HYSYS V9.0 simulation software has been performed and is reported in Figure 12.

Figure 12 demonstrates the reliability of the computational method for He-containing mixtures. Very small differences between the two models can be appreciated, probably due to
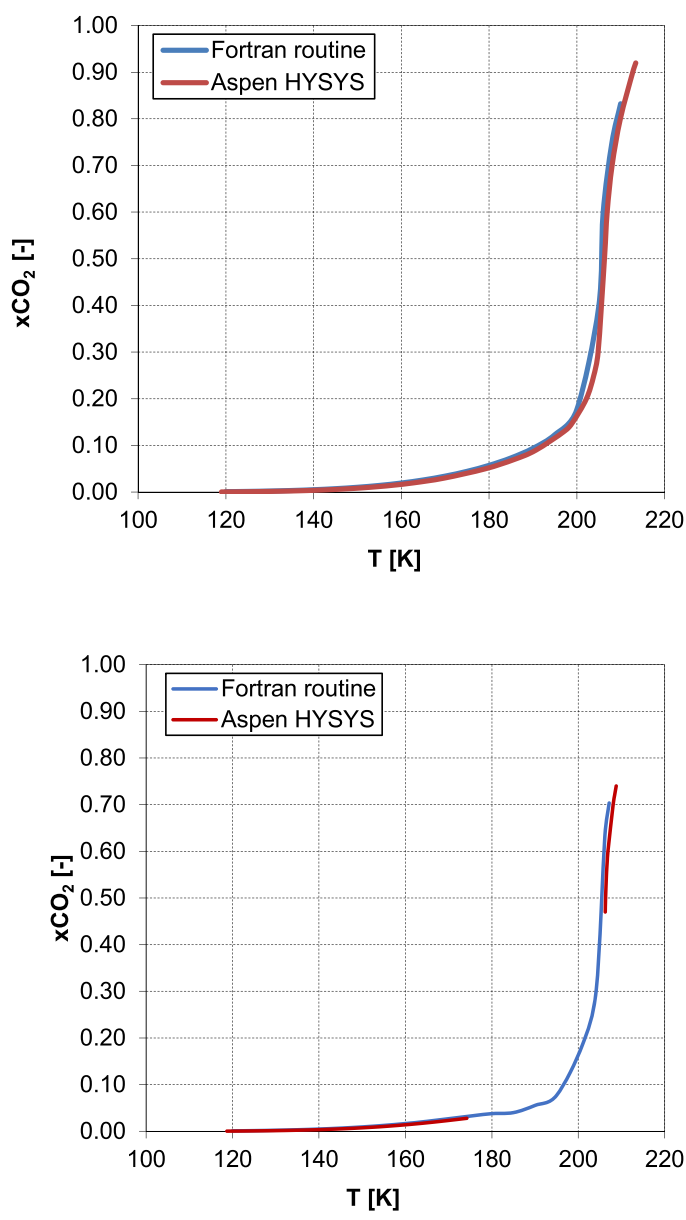

b)

Figure 12. $\mathrm{CO}_{2}$ solubility $\left(x_{\mathrm{CO}_{2}}\right)$ vs temperature $T$ for the $\mathrm{CH}_{4}-\mathrm{N}_{2}-$ $\mathrm{He} \mathrm{CO}_{2}$ mixture. Comparison between models for (a) $\mathrm{N}_{2}=5 \mathrm{~mol} \%$, $\mathrm{He}=2 \mathrm{~mol} \%$ and (b) $\mathrm{N}_{2}=25 \mathrm{~mol} \%, \mathrm{He}=0.5 \mathrm{~mol} \%$. 
the intrinsically different quantum correction implemented, which is proprietary for Aspen HYSYS.

However, Aspen HYSYS simulation software shows a convergence problem in the middle temperature range, between 170 and $210 \mathrm{~K}$. On the other hand, no numerical problems are registered with the developed computational Fortran routine.

\section{CONCLUSIONS}

In this work, the effect of light gases (namely, $\mathrm{N}_{2}$ and $\mathrm{He}$ ) on $\mathrm{CO}_{2}$ solidification has been evaluated through a developed computational method based on the classical approach (CA) for SLVE.

PREoS has been selected to characterize the fluid-phase equilibria.

$\mathrm{CH}_{4}-\mathrm{N}_{2}-\mathrm{CO}_{2}$ and $\mathrm{CH}_{4}-\mathrm{N}_{2}-\mathrm{He}-\mathrm{CO}_{2}$ mixtures have been considered for this purpose, varying the $\mathrm{N}_{2}$ and $\mathrm{He}$ content in line with typical natural gas compositions.

Helium behavior as a quantum gas has been accounted for, introducing a suitable modification of pure-component critical parameters.

The presence of helium in the analyzed mixture is responsible for a minimum trend in the pressure-temperature equilibrium loci. In the lowest considered temperature range, below $130 \mathrm{~K}$, a small variation in the equilibrium temperature as well as in the helium content in the liquid phase corresponds to an abrupt increase in the SLVE pressure.

As observed for $\mathrm{N}_{2}$, He facilitates $\mathrm{CO}_{2}$ solidification, reducing $\mathrm{CO}_{2}$ solubility and increasing the triphasic equilibrium pressure. However, its effect on solid deposit formation is much more evident than in the case of nitrogen. Even small amounts of helium can be responsible for $\mathrm{CO}_{2}$ freezing phenomena, causing equipment damage within the helium recovery section, the last one of the natural gases to the grid purification unit.

In summary, since $\mathrm{CO}_{2}$ freezing cannot be excluded a priori, $\mathrm{CO}_{2}$ content in the feed mixture and process operating conditions have to be carefully managed, keeping in mind the SLVE conditions for helium-bearing natural gas mixtures.

\section{AUTHOR INFORMATION}

\section{Corresponding Author}

Laura A. Pellegrini - GASP - Group on Advanced Separation Processes \& GAS Processing, Dipartimento di Chimica, Materiali e Ingegneria Chimica "G. Natta", Politecnico di Milano, 20133 Milano, Italy; (c) orcid.org/0000-00022188-9086; Phone: +39 022399 3237;

Email: laura.pellegrini@polimi.it; Fax: +39 0223993280

\section{Author}

Elvira Spatolisano - GASP - Group on Advanced Separation Processes \& GAS Processing, Dipartimento di Chimica, Materiali e Ingegneria Chimica "G. Natta", Politecnico di Milano, 20133 Milano, Italy; 이이.org/0000-00023316-0487

Complete contact information is available at: https://pubs.acs.org/10.1021/acs.jced.1c00326

\section{Notes}

The authors declare no competing financial interest.

\section{REFERENCES}

(1) Grynia, E.; Griffin, P. J. Helium in Natural Gas- Occurrence and Production. J. Natural Gas Eng. 2016, 1 (2), 163-215.

(2) Mineral Commodity Summaries, 2020: U.S. Geological Survey, DOI: $10.3133 / \operatorname{mcs} 2020$.

(3) Smith, D. M.; Goodwin, T. W.; Schillinger, J. A. Challenges to the worldwide supply of helium in the next decade. AIP Conf. Proc. 2003, 710, 119.

(4) Chrz, V. Helium Recovery. International Course of Cryogenics, 2nd part; CERN: Geneva, 2010.

(5) Kidnay, A. J.; Parrish, W. R. Fundamentals of Natural Gas Processing; Taylor and Francis Group, LLC, 2006; pp 199-214.

(6) Haüssinger, P.; Glatthaar, R.; Rhode, W.; Kick, H.; Benkmann, C.; Weber, J.; Wunschel, H. J.; Stenke, V.; Leicht, E.; Stenger, H. Noble Gases. In Ullmann's Encyclopedia of Industrial Chemistry; WileyVCH: Weinheim, Germany, 2005.

(7) Kim, D. Helium Extraction from LNG End Flash; NTNU, Norwegian University of Science and Technology, 2014.

(8) Brandt, L. W.; Stroud, L.; Miller, J. E. Data for Two HeliumBearing Natural Gases. J. Chem. Eng. Data 1961, 6, 6-13.

(9) Zartman, R. E.; Wasserburg, G. J.; Reynolds, J. H. Helium, Argon and Carbon in some natural gases. J. Geophys Res. 1961, 66, 277-306.

(10) Rufford, E. T.; Chan, K. I.; Huang, S. H.; May, E. F. A Review of Conventional and Emerging Process Technologies for the Recovery of Helium from Natural Gas. Adsorpt. Sci. Technol. 2014, 32, 49-72.

(11) Pacheco, N.; Thomas, D. Minerals Yearbook-Helium (Advance Release); U.S. Geological Survey: Reston, VA, 2009.

(12) De Guido, G.; Messinetti, F.; Spatolisano, E. Cryogenic Nitrogen Rejection Schemes: Analysis of Their Tolerance to $\mathrm{CO}_{2}$. Ind. Eng. Chem. Res. 2019, 58, 17475-17488.

(13) Spatolisano, E.; Pellegrini, L. A. $\mathrm{CO}_{2}$-Tolerant Cryogenic Nitrogen Rejection Schemes: Analysis of Their Performances. Ind. Eng. Chem. Res. 2021, 60 (11), 4420-4429.

(14) Peng, D.; Robinson, D. A new two parameters equation of state. Ind. Eng. Chem. Fundam. 1976, 15, 59-64.

(15) Plee, V.; Jaubert, J.-N.; Privat, R.; Arpentinier, P. Extension of the E-PPR78 equation of state to predict fluid phase equilibria of natural gases containing carbon monoxide, helium-4 and argon. J. Pet. Sci. Eng. 2015, 133, 744-770.

(16) Chueh, P. L.; Prausnitz, J. M. Vapor-Liquid Equilibria at High Pressures. Vapor-Phase Fugacity Coefficients in Nonpolar and Quantum-Gas Mixtures. Ind. Eng. Chem. Fundam. 1967, 6, 492-498.

(17) Gunn, R. D.; Chueh, P. L.; Prausnitz, J. M. Prediction of thermodynamic properties of dense gas mixtures containing one or more of the quantum gases. AIChE J. 1966, 12, 937-941.

(18) Prausniz, J. M.; Lichtenthaler, R. N.; de Azevedo, E. G. Molecular Thermodynamics of Fluid-Phase Equilibria, 3rd ed.; Prentice Hall PTR: New Jersey, 1999.

(19) Campestrini, M. Thermodynamic study of solid-liquid-vapor equilibrium: application to cryogenics and air separation unit. Chemical and Process Engineering; Ecole Nationale Supérieure des Mines de Paris, 2014.

(20) Kan, K. An equation of state and the gas-liquid-solid equilibrium in argon. Chin. J. Phys. 1979, 17, 32-43.

(21) Salim, P.; Trebble, M. Modeling of solid phases in thermodynamic calculations via translation of a cubic equation of state at the triple point. Fluid Phase Equilib. 1994, 93, 75-99.

(22) Yokozeki, A. Analytical equation of state for solid-liquid-vapor phases. Int. J. Thermophys. 2003, 24 (3), 589-620.

(23) Soave, G. S. Application of the Redlich-Kwong-Soave equation of state to solid-liquid equilibria calculations. Chem. Eng. Sci. 1979, 34 (2), 225-229.

(24) De Guido, G.; Langè, S.; Moioli, S.; Pellegrini, L. A. Thermodynamic method for the prediction of solid $\mathrm{CO}_{2}$ formation from multicomponent mixtures. Process Saf. Environ. Prot. 2014, 92, $70-79$.

(25) De Guido, G.; Langè, S.; Moioli, S.; Pellegrini, L. A. Calculation of $\mathrm{CO}_{2}$ freezing points in mixtures using SRK and PR EoSs. J. Energy Challenges Mech. 2014, 1, 3. 
(26) Pellegrini, L. A.; Moioli, S.; Gamba, S.; Ceragioli, P. Prediction of vapor-liquid equilibrium for reservoir mixtures with cubic equations of state: Binary interaction parameters for acidic gases. Fluid Phase Equilib. 2012, 326, 45-49.

(27) AspenTech Aspen Hysys; AspenTech: Burlington, MA, 2016.

(28) Riva, M.; Stringari, P. Experimental study of the influence of nitrogen and oxygen on the solubility of solid carbon dioxide in liquid and vapor methane at low temperature. Ind. Eng. Chem. Res. 2018, 57, 4124-4131.

(29) Eggeman, T.; Chafin, S. Pitfalls of $\mathrm{CO}_{2}$ Freezing Prediction. 82nd Annual Convention of Gas Processors Association; San Antonio, TX, March 10, 2003.

(30) Kunz, O.; Klimeck, R.; Wagner, W.; Jaeschke, M. The GERG2004 Wide-Range Equation of State for Natural Gases and Other Mixtures; GERG Technical Monograph 15, 2007.

(31) Rowland, D.; Hughes, T. J.; May, E. F. Effective Critical Constants for Helium for Use in Equations of State for Natural Gas Mixtures. J. Chem. Eng. Data 2017, 62, 2799-2811.

(32) Twu, C. H.; Coon, J. E.; Harvey, A. H.; Cunningham, J. R. An Approach for the Application of a Cubic Equation of State to Hydrogen- Hydrocarbon Systems. Ind. Eng. Chem. Res. 1996, 35, 905-910.

(33) McCarty, R. D.; Arp, V. D. A New Wide Range Equation of State for Helium. Adv. Cryog. Eng. 1990, 35, 1465-1475.

(34) Graboski, M. S.; Daubert, T. E. A modified Soave equation of state for phase equilibrium calculations. 3. Systems containing hydrogen. Ind. Eng. Chem. Process Des. Dev. 1979, 18, 300-306.

(35) Radosz, M.; Lin, H. M.; Chao, K. C. High-pressure vapor-liquid equilibriums in asymmetric mixtures using new mixing rules. Ind. Eng. Chem. Process Des. Dev. 1982, 21, 653-659.

(36) Schulze, W. A. Simple generalization of the binary temperature dependent interaction parameters in the Soave-Redlich-Kwong and Peng-Robinson equations of state for helium-mixtures. Fluid Phase Equilib. 1993, 87, 199-211.

(37) Qian, J. W.; Jaubert, J. N.; Privat, R. Phase equilibria in hydrogen-containing binary systems modeled with the Peng-Robinson equation of state and temperature-dependent binary interaction parameters calculated through a group-contribution method. J. Supercrit. Fluids 2013, 75, 58-71. 